\title{
Effects of amino acids on the growth of an anaerobic rumen fungus Neocallimastix sp $\mathbf{N} 13$
}

\author{
A Onoda, Y Kobayashi, S Hoshino * \\ Faculty of Bioresources, Mie University, Tsu, Mie 514, Japan
}

(Received 2 January 1996; accepted 25 March 1996)

\begin{abstract}
Summary - The amino acid requirements of Neocallimastix $\mathrm{sp} N 13$ isolated from sheep rumen were studied using supplements containing either ten essential amino acids (10 EAA) or eight nonessential amino acids (8 NEAA), or both (18 AA). Although the fungus could grow in a medium containing ammonium sulphate as the sole source of nitrogen, amino acid supplements, especially $18 \mathrm{AA}$, greatly stimulated its growth. Omission of the sulphur-containing amino acids (SCAA) from the 18 AA mixture markedly reduced the growth-stimulating effect, and sulphide, but not sulphate, substituted for SCAA only partly compensated for this omission. Omission of aromatic, branched chain, basic, acidic, aliphatic and hydroxy amino acids, and proline, singly or in combination, all reduced fungal growth to some degree as compared with the 18 AA supplement. A three amino acid (leucine, methionine and histidine) supplement was a potent stimulator for the fungus, whereas another three amino acid combination (glutamic acid, methionine and serine) was ineffective. The results indicated that Neocallimastix sp N 13 effectively utilized amino acids for its growth, but the requirements for the different amino acids differed from those of $N$ patriciarum.
\end{abstract}

rumen fungus / Neocallimastix / amino acids / growth / sheep

Résumé - Effets des acides aminés sur la croissance du champignon anaérobie Neocallimastix sp $\mathbf{N} 13$ isolé du rumen du mouton. Les besoins en acides aminés de Neocallimastix sp N13 isolé du rumen de mouton ont été étudiés en utilisant des suppléments contenant soit dix acides aminés essentiels (10 EAA), soit huit acides aminés non essentiels (8 NEAA), soit les deux (18 AA). Bien que le champignon puisse croitre sur un milieu contenant du sulfate d'ammonium comme seule source d'azote, les suppléments d'acides aminés, particulièrement 18AA, ont considérablement stimulé sa croissance. L'omission des acides aminés soufrés (SCAA) dans le mélange 18AA a réduit nettement l'effet stimulateur sur la croissance, alors que les sulfures, mais pas les sulfates, substitués aux SCAA compensaient seulement en partie cette omission. La suppression des acides aminés aromatiques, à chaîne ramifiée, basiques, acides, aliphatiques et des hydroxyaminoacides et de la proline, seuls ou combinés, a réduit la croissance du champignon par rapport à l'effet des 18AA. Un supplément de trois

\footnotetext{
${ }^{*}$ Correspondence and reprints
} 
acides aminés (leucine, méthionine, histidine) avait un pouvoir stimulateur, tandis qu'une autre combinaison de trois acides aminés (acide glutamique, méthionine, sérine) était sans effet. Les résultats ont montré que Neocallimastix sp N 13 utilisait effectivement les acides aminés pour sa croissance, mais les besoins pour les différents acides aminés diffèrent de ceux de $\mathrm{N}$ patriciarum.

\section{champignon du rumen / Neocallimastix / acide aminé / croissance / mouton}

\section{INTRODUCTION}

The free- and protein component-amino acid contents of anaerobic rumen fungi Neocallimastix frontalis and Piromyces communis are comparable to those of casein and lucern leaf protein (Kemp et al, 1985). We have also confirmed that the amino acid profiles of Neocallimastix $\mathrm{sp}$, Piromyces $\mathrm{sp}$ and Caecomyces $\mathrm{sp}$ resemble one another and are similar to those of rumen protozoa. They are characterized by a high lysine content as compared with rumen bacterial proteins (Onoda et al, 1993). Moreover, fresh rumen fungi infused into the abomasum are extensively digested (Gulati et al, 1989). These findings suggest that the rumen fungi may substantially contribute to the amino acid supply for their host animals if notable amounts of fungi are transferred from the rumen to the lower gut.

Orpin and Greenwood (1986) demonstrated that amino acid supplements to the defined minimal medium (consisting of ammonium ion, haemin, vitamins and a reduced source of sulphur) greatly stimulate the growth of Neocallimastix patriciarum. The rumen fungi Neocallimastix sp can take up amino acids and incorporate them into proteins without requiring any modification of the amino acids (Gulati et al, 1989). When a mixture of $L-(U-14 C)$ amino acids was added to cultures of rumen fungi, the radioactivity was later found located in the cellular proteins, lactate, volatile fatty acids and ethanol (Marounek and Vovk, 1992). Thus, it is highly probable that rumen fungi can synthesize their cellular proteins from amino acids which were either taken up from the surrounding environment or synthesized in the cell, or both, and that a performed amino acid supply is favourable for the rapid growth of fungi. However, the amino acid requirement of rumen fungi has not yet been fully elucidated, except that cysteine and cysteine-like compounds support the growth of Neocallimastix sp (Phillips and Gordon, 1991).

Maeng et al (1976) reported that substitutions of amino acid mixtures for urea stimulate rumen bacterial growth in vitro, the stimulation being greatest when a mixture of 18 amino acids (18 AA) was substituted for urea, followed by a mixture of ten essential amino acids (10 EAA) and of eight nonessential amino acids (8 NEAA). These amino acids are known to be essential or nonessential for the growth of rats and other mammals.

Argyle and Baldwin (1989) also demonstrated that rumen bacterial growth is greatly stimulated by the complete amino acid mixture consisting of $18 \mathrm{AA}$ and two amides, and growth stimulation from amino acids is due to the number of amino acids provided in a given mixture rather than specific growth limiting amino acids. Fujimaki et al (1989, 1992) confirmed these previous findings and found that an amino acid mixture (leucine, methionine and histidine) is comparable to the mixture of 10 EAA in stimulating bacterial growth yields.

In the present paper, we describe the effects of different amino acid supplements, which have been found to be effective for rumen bacterial growth, on the growth of a sheep ruminal fungus, Neocallimastix $\mathrm{sp} \mathrm{N}$ 13. 


\section{MATERIALS AND METHODS}

\section{Fungus and culture}

Neocallimastix sp $\mathrm{N} 13$ was isolated from the rumen of fistulated crossbred (Corriedale $x$ Suffolk) sheep fed a diet of $400 \mathrm{~g}$ concentrate and $600 \mathrm{~g}$ lucern hay cubes daily. The isolated fungus was maintained anaerobically in Joblin's medium (1981) in which cellobiose was replaced with cellulose in the form of Toyo No 1 filter paper (equivalent to Whatman No 1) and including the antibiotics (ampicillin: $0.09 \mathrm{~g} / \mathrm{L}$, chloramphenicol: $0.09 \mathrm{~g} / \mathrm{L}$ and streptomycin: $0.09 \mathrm{~g} / \mathrm{L}$ ). Stock cultures were subcultured every 6 days, enabling the isolate to retain its ability to use cellulose and proliferate.

Neocallimastix $\operatorname{sp~} \mathrm{N} 13$ was grown on liquid Joblin's medium (1981) for 3 days and then zoospores were harvested anaerobically by filtrating the cultures through nylon meshes (10 $\mu \mathrm{m})$. The filtrate containing the zoospores $(0.3$ $\mathrm{ml}$ ) was inoculated into $5 \mathrm{ml}$ of a basal medium in sealed Hungate tubes $(100 \times 6 \mathrm{~mm})$ with or without amino acid present and after the addition of $0.2 \mathrm{ml}$ of an antibiotic solution containing ampicillin $(0.25 \%)$, chloramphenicol $(0.25 \%)$ and streptomycin sulfphate $(0.25 \%)$; it was incubated anaerobically at $39^{\circ} \mathrm{C}$ for at least 5 days. Although the fungal culture was definitely axenic, the antibiotics were added to the culture for possible contamination. The basal medium consisted of a salt solution $\mathrm{A}(34.0 \mathrm{ml})$ and $\mathrm{B}(34.0 \mathrm{ml})$ (Hungate, 1969), cellobiose $(0.4 \mathrm{~g}), \mathrm{NaHCO}_{3}(1.0 \mathrm{~g}), 0.05 \%$ haemin solution $(0.8 \mathrm{ml}), \mathrm{Na}_{2} \mathrm{~S} .9 \mathrm{H}_{2} \mathrm{O}(0.08 \mathrm{~g})$, vitamins $(2.10 \mathrm{ml})$ and a volatile fatty acid solution (14.0 ml) for rumen bacteria (RGCMSA medium) (Hungate, 1969), $0.1 \%$ resazurin solution $(0.2 \mathrm{ml})$ and distilled water $(125.9 \mathrm{ml})$. The sole nitrogen source of the basal medium was ammonium sulphate $(12 \mathrm{~g} / \mathrm{L})$ from salt solution $B$.

\section{Amino acid supplements}

Each of the L-amino acids was dissolved in either $0.1 \mathrm{M} \mathrm{HCl}$ or $0.1 \mathrm{M} \mathrm{NaOH}$ at a concentration of $0.1 \mathrm{M}$ except for aspartic acid $(0.07 \mathrm{M})$ and tyrosine $(0.05 \mathrm{M})$ and mixed to give an equal molar mixture. The 10 EAA consisted of arginine (Arg), histidine (His), isoleucine (lle), leucine (Leu), lysine (Lys), methionine (Met), phenylalanine (Phe), threonine (Thr), tryptophan (Trp) and valine (Val), while the 8 NEAA contained alanine (Ala), aspartic acid (Asp), cysteine (Cys), glutamic acid (Glu), glycine (Gly), proline (Pro), serine (Ser) and tyrosine (Tyr). The 18 AA was made up of both 10 EAA and 8 NEAA. The $\mathrm{pH}$ value of these and other amino acid mixtures was adjusted to 6.8 prior to use in the incubations.

To compare the effect of the different amino acid supplements on the rate of fungal growth, the amino acid mixtures were added to the basal medium to give an equal concentration of amino acid $(5 \mathrm{mg} / \mathrm{ml}$ medium: experiment 1$)$ or aminonitrogen $(0.69 \mathrm{mg} / \mathrm{ml}$ medium: experiments 2-4). The control tubes without amino acid supplement contained only basal medium which had ammonium sulphate $(0.41 \mathrm{mg} / \mathrm{ml})$ as a nitrogen source.

In experiment (Exp) 1 , the rates of fungal growth for the three amino acid supplements (18 AA, 10 EAA and 8 NEAA) were compared with that of a control. Since the most effective supplement was $18 \mathrm{AA}$, the amino acid requirement for fungal growth was evaluated by the sequential omission of an amino acid or an amino acid group from the 18 AA medium. Special amino acid combinations (Lys + Met + His or Glu + Met + Ser) were also tested.

\section{Analytical procedures}

During the 5 day incubation, fungal protein and chitin levels were determined every day to evaluate growth rates. The culture tube was centrifuged (2 $200 \mathrm{~g}$ for $15 \mathrm{~min}$ ) and the resultant supernatant was saved for amino acid analysis. The precipitate was washed with distilled water four times, dried overnight at $100^{\circ} \mathrm{C}$, dissolved by standing in $1 \mathrm{M} \mathrm{NaOH}$ solution at $100^{\circ} \mathrm{C}$ for $5 \mathrm{~min}$ and then centrifuged ( $2200 \mathrm{~g}$ for $15 \mathrm{~min}$ ). The aliquots were used for protein determination as described by Lowry et al (1951). The residual precipitate was washed four times with distilled water, dried overnight at $100^{\circ} \mathrm{C}$, hydrolyzed by heating at $100^{\circ} \mathrm{C}$ for $4 \mathrm{~h}$ with $6 \mathrm{M} \mathrm{HCl}$ solution and filtered through Toyo No 1 filter paper. The filtrate was dried in vacuo and the residue was dissolved in distilled water for the determination of the amount of fungal chitin using the method of Chen and Johnson (1983) with glucosamine as the standard. The amino acids in the culture medium were analyzed by an o-phthal-aldehyde 
method with the aid of high performance liquid chromatography (Tosoh Co, Japan).

\section{Statistical analysis}

The results were analyzed by analysis of variance and Duncan's multiple range test, whenever appropriate.

\section{RESULTS}

\section{Exp 1: 18 AA, 10 EAA and 8 NEAA sup- plements}

The amino acid supplements were considered to have stimulated fungal growth when it was estimated that the amount of fungal chitin was significantly different from the control after day 2 of the incubation (fig 1). The complete mixture (18 AA) was the most effective of the three supplements, and the growth rate on day 2 was two and six times higher than 10 EAA and 8 NEAA, respectively (fig 1). When the fungal growth rate was expressed in terms of protein $\mu \mathrm{g} / \mathrm{tube}$, the results were virtually identical with those as mentioned earlier (data not shown). The correlation coefficient between chitin and protein levels produced was 0.83 and significant $(P<0.01, n=176)$ for this fungus species. Thus, the fungal growth rates in the following experiments were expressed as fungal protein increases during incubation. This allowed us to handle a large number of incubation tubes.

\section{Exp 2: Omission of sulphur-containing amino acids (SCAA), aromatic amino acids (AAA) and branched chain amino acids (BCAA) from 18 AA}

Omission of SCAA greatly suppressed fungal growth to the level of control which con- tained no amino acid (fig 2). Omission of AAA also suppressed the early growth of the fungus, while the suppressing effect of BCAA omission was observed only in day 2 cultures (fig 2). Either Met- or Cys-omission had less of an effect than the complete SCAA-omission. The replacement of SCAA by sodium sulphide, but not sodium sulphate, was partly effective at stimulating fungal growth (fig 3).

Omission of one AAA from the 18 AA supplement reduced fungal growth, and was significantly lower than 18 AA on days 2 and 3 (fig 4). Cultures lacking two AAA (Phe, Trp: Phe, Tyr: Trp, Tyr) had a greater growth reduction than those where only one AAA was omitted (data not shown).

Omission of BCAA from the 18 AA supplement had no appreciable effect on fungal growth except for the day 2 cultures (fig 2).

\section{Exp 3: Omission of basic, acidic, alphatic and hydroxy amino acids and proline}

Omission of the basic amino acids, singly or in combination, reduced fungal growth significantly; His and Lys had a greater effect than Arg (fig 5). Omission of Asp or Glu, or both from the 18 AA supplement reduced fungal growth during its later stages, days 3 to 5 (fig 6). When Ala or Gly, or both were removed from the $18 \mathrm{AA}$ supplement, the growth curves obtained were similar to those for acidic amino acid omission (fig 7).

Omission of Thr or both Thr and Ser induced a slight but significant growth retardation in days 3 and 4 cultures, whereas in the case of Ser, no growth inhibition was observed (fig 8). Cultures lacking Pro also demonstrated a slight growth inhibition on days 3 and 4 as compared to 18 AA cultures (fig 9). 

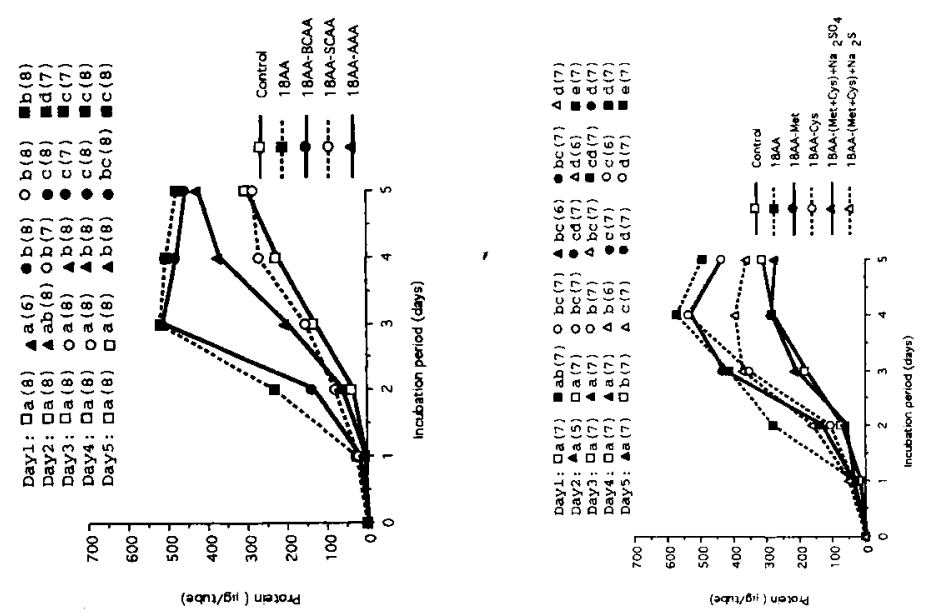

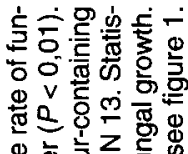

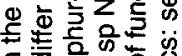
ธ흐을 里可응 要

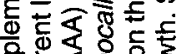

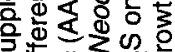
के

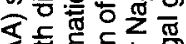
委责 등응 出

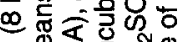
을 可

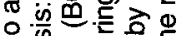
웅

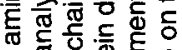

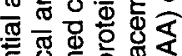
政类 \%

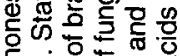
我 动之。응 की 둥. 舫

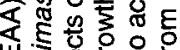

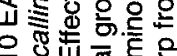

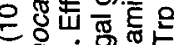
क ⿻ ㇒ i

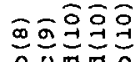
(1)

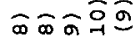
\%०ण 0000

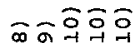
\% बิธลจำ ช。 $\ddot{\sim} \ddot{\sim} \ddot{\sim} \ddot{\sim}$

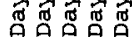

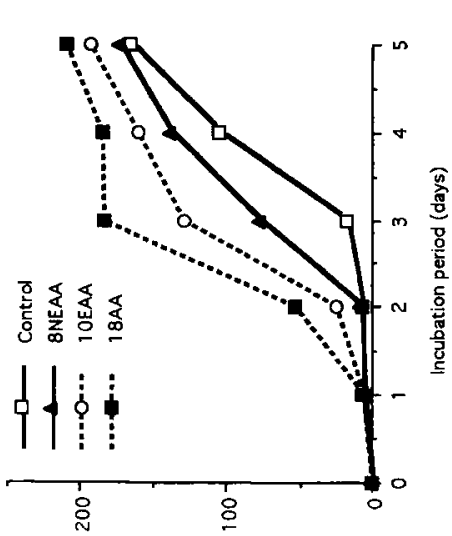

(วqm16ri) 4!!14ว

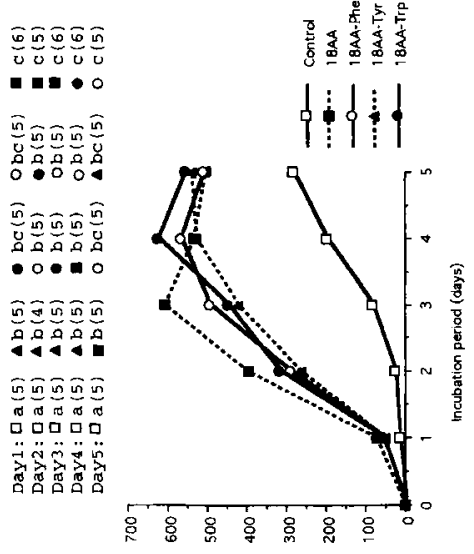

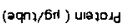

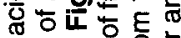
응 영몬 둥

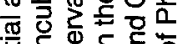
드에 웅응

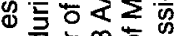

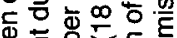

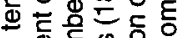
安要 ४웡 $\infty$ 엉 엉

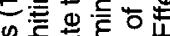
능 贾

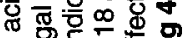
든 造的-

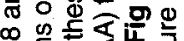
통

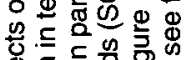

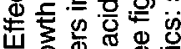

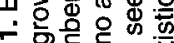

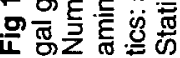




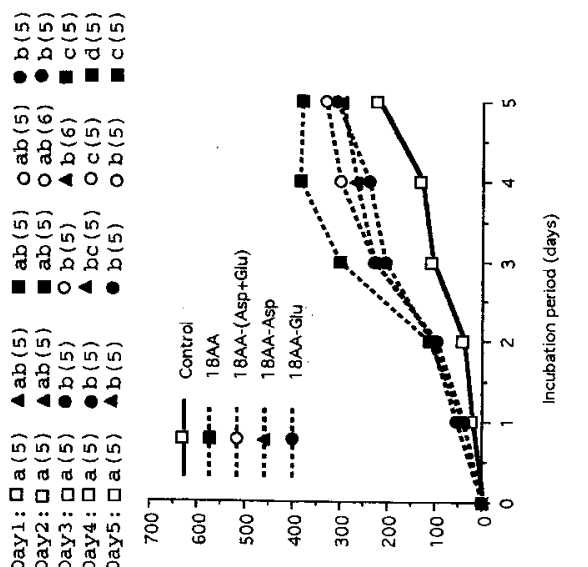

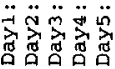

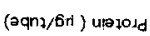

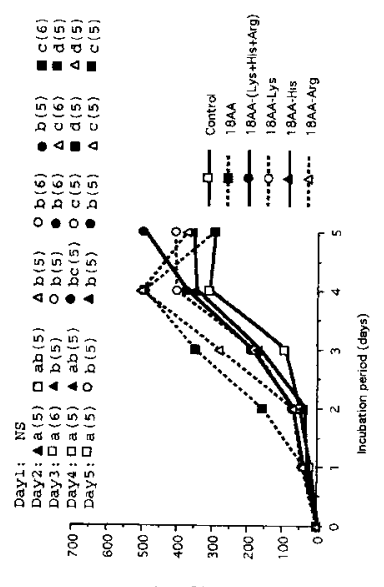

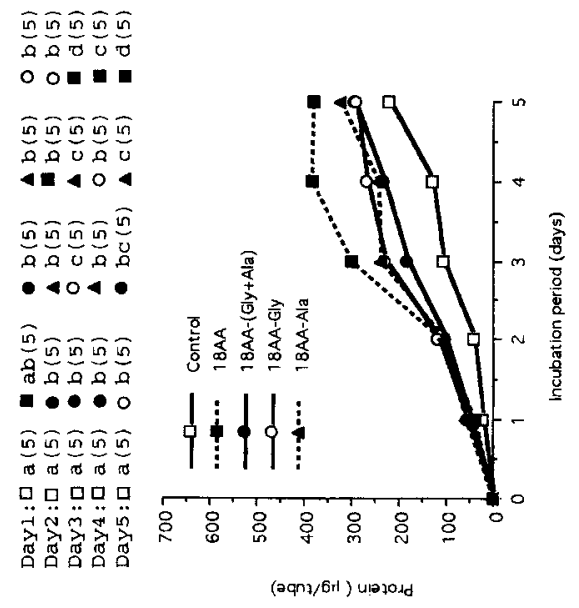

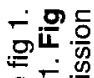

$\$$

i. 뭉

is: 은

垔

के

$=\infty$

焉这

ठญ

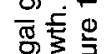

을 은

흐용

密 它

눙

要昰

文案

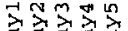

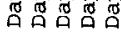

(aqnz/6n) uाəz̧01d

的券 至家 융

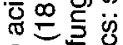
응믐은 중 $\infty$ 응 它这 ह $\frac{\mathrm{c}}{\mathrm{c}}$ 은 흥 응 है

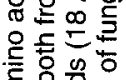

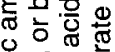
온 50 可产 Чัㅎํ 등 它造文文 帝 흘 은 을 등해응은 등휴 ㄴㅎํ츨 후웡 新焉 등ㅎㅇ응 忽 윤들 동 $+\overline{0}$ एक है 융흔

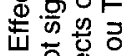

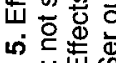

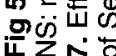




\section{Exp 4: Supplements consisting of three amino acids}

An equal molar mixture of Lys, Met and His $(\mathrm{LMH})$, that is as powerful as the $10 \mathrm{EAA}$ supplement for rumen bacterial proliferation (Fujimaki et al, 1992), stimulated fungal growth at a level comparable to $18 \mathrm{AA}$ (fig 10). The other supplement consisting of Glu, Met and Ser (GMS), each of which has proven to be a significant growth stimulator for Neocallimastix patriciarum (Orpin and Greenwood, 1986), was not effective at stimulating the growth of Neocallimastix sp N 13 (fig 11).

\section{Amino acid concentrations in culture medium with 18 AA supplement during incubation}

The concentration of Met, Cys, Arg, lle and Leu decreased rapidly and that of the other amino acids except Ala decreased gradually during the 5 day incubation. In contrast, Ala concentration gradually increased up to the end of incubation (data not shown).

\section{DISCUSSION}

The present fungus isolate, Neocallimastix sp $\mathbf{N} 13$ could survive and grow in a medium containing ammonium sulphate as its sole nitrogen source and sulphide. This result was similar to that for Neocallimastix patriciarum reported by Orpin and Greenwood (1986), suggesting that this fungus as well as most of the rumen bacteria can synthesize amino acids from ammonia and minerals. This view is supported by the finding that labelled sulphide is incorporated into Cys and Met in batch culture of Neocallimastix sp LM 1 from sheep rumen (Gulati et al, 1989). The amino acid synthesis in $N$ sp $\mathrm{N} 13$, however, seems to be a costly and time-consuming process, because amino acid supplements greatly stimulated fungal growth at an earlier stage of incubation in comparison with control without supplements (fig 1).

The effect of amino acid supplements on fungal growth was greatest with the $18 \mathrm{AA}$ supplement, followed by the 10 EAA and the 8 NEAA supplement (fig 1). The EAA were more effective in stimulating fungal growth than the NEAA (figs 2 and 3). These results are in general agreement with those reported for rumen bacteria (Maeng et al, 1976; Argyle and Baldwin, 1989; Fujimaki et al, 1989, 1992), implying that rumen fungi would compete with bacteria for amino acids.

The findings that SCAA (Met, Cys) are potent stimulators for the growth of $N \mathrm{sp} \mathrm{N}$ 13 and that sulphide, but not sulphate, can partially replace SCAA (figs 2 and 3 ) are in good agreement with the results from studies on N patriciarum (Orpin and Greenwood, 1986) and N sp LM 1 (Phillips and Gordon, 1991). The basal medium contained a sufficient amount of $\mathrm{Na}_{2} \mathrm{~S}$ but the addition of 17 AA containing either Cys or Met greatly stimulated growth as compared to the control culture in basal medium (fig 3), suggesting that the fungus requires these amino acids for rapid growth despite the fact that reducing conditions in the culture were maintained with reductants such as $\mathrm{Na}_{2} \mathrm{~S}$. Such is the case with $N$ sp LM 1 which grows better with sulphide plus Met or Cys than with sulphide alone (Phillips and Gordon, 1991). Therefore, the vital requirement for sulphur in rumen fungi (Akin et al, 1983) may in fact be for SCAA.

In addition to SCAA, omission of aromatic, branched chain, basic, acidic, alphatic and hydroxy amino acids or amino acid from the 18 AA supplement (figs 4-9), all decreased the rate of fungal growth to some degree, suggesting that the fungus utilizes these amino acids for rapid growth, though the precise metabolic processes 


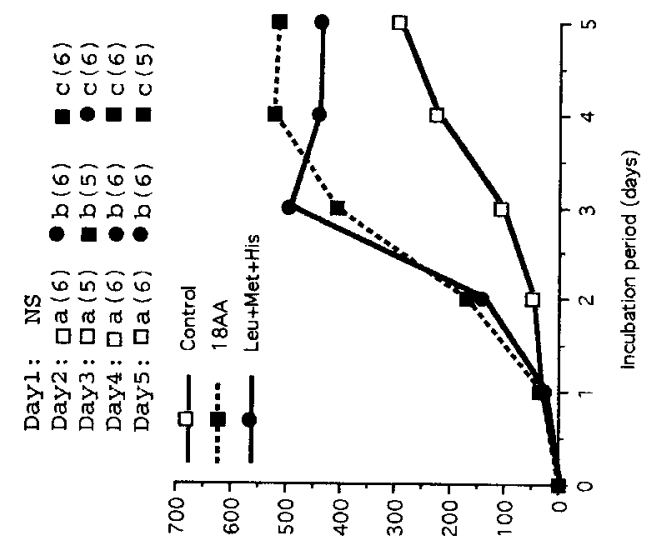

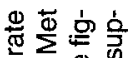

迹娄

ᄃ

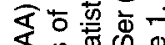

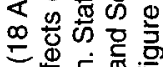

密专

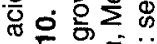

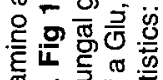

का -

这

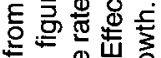

\%

응 क व

웅

을

.

है क 응 을

둥

용 응

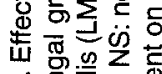

कi

운흥 흥

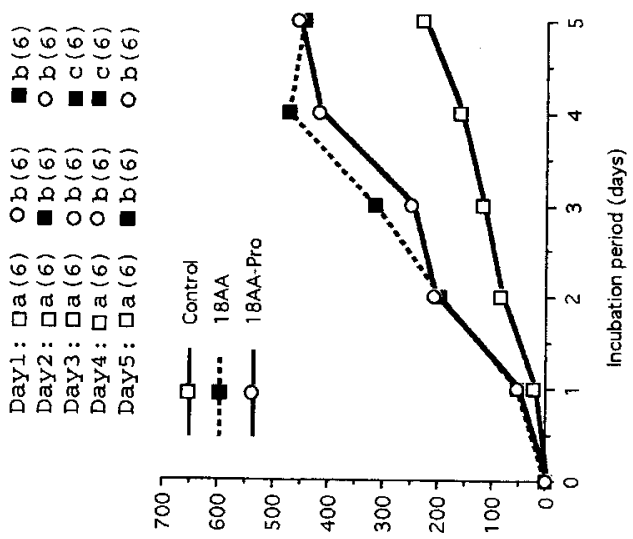

(aqn)/6ri) u!aาoid

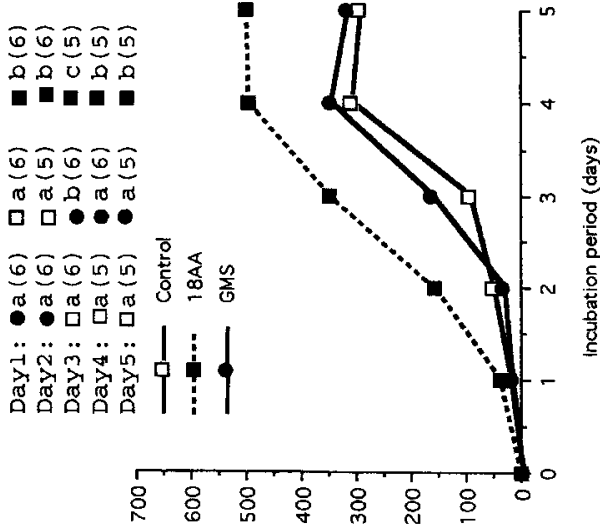

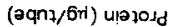


remain to be clarified. It is possible that under in vivo conditions the fungus may take up amino acids and utilize them for protein synthesis, aided by proteolysis by the fungi themselves or by bacteria. Several workers have observed that a few rumen fungi including Neocallimastix $\mathrm{sp}$ have extracellular proteolytic activity (Wallace and Joblin, 1985; Asao et al, 1993; Michel et al, 1993; Yanke et al, 1993). However, it is obscure at present to what extent fungal proteolysis contributes to amino acid release in the rumen.

It should be noted that an amino acid combination (Lys + Met + His: LMH) was just as effective for fungal growth as the 18 AA supplement (fig 10). Since the $\mathrm{LMH}$ combination also increases rumen bacterial yields (Fujimaki et al, 1992), this combination may be useful as a less expensive supplement for increasing rumen microbial biomass.

In contrast to Neocallimastix patriciarum (Orpin and Greenwood, 1986), a Glu, Met and Ser (GMS) combination supplement was ineffective at increasing the growth rate in the present fungus, suggesting that both Met and Glu are effective for the growth of $N$ sp N 13 only when the media contain other amino acids (figs 2, 3 and 6), and that the nutritional requirements of Neocallimastix sp differ with different strains. It is possible, however, that differences in medium components may have affected the amino acid requirements of these $N$ sp strains. Further study is needed to elucidate the amino acid requirements of rumen fungi, which will lead to a better understanding of rumen ecosystems.

\section{ACKNOWLEDGMENTS}

This study was supported in part by a grant-inaid for scientific research (no 06660353) from the Ministry of Education, Science and Culture of Japan.

\section{REFERENCES}

Akin DE, Gordon GLR, Hogan JP (1983) Rumen bacterial and fungal degradation of Digitaria pentzii grown with or without sulfur. Appl Environ Microbiol $46,738-748$

Argyle JL, Baldwin RL (1989) Effects of amino acids and peptides on rumen microbial growth yields. J Dairy Sci 72, 2017-2027

Asao N, Ushida K, Kojima Y (1993) Proteolytic activity of rumen fungi belonging to the genera Neocallimastix and Piromyces. Lett Appl Microbiol 16, 247250

Chen SC, Johnson BR (1983) Improved colorimetric determination of cell wall chitin in wood decay fungi. Appl Environ Microbiol 46, 13-16

Fujimaki T, Kobayashi Y, Wakita M, Hoshino S (1989) Influence of amino acid supplement on cellulolysis and microbial yield in sheep rumen. $J$ Anim Physiol Anim Nutr 62, 119-124

Fujimaki T, Kobayashi Y, Wakita M, Hoshino S (1992) Amino acid supplements: a least combination that increases microbial yields of washed cell suspension from goat rumen. J Anim Physiol Anim Nutr 67, 41-50

Gulati SK, Ashes JR, Gordon GLR, Connell PJ, Rogers PL (1989) Nutritional availability of amino acids from the rumen anaerobic fungus Neocallimastix sp LM1 in sheep. J Agric Sci (Camb) 113, 383-387

Hungate RE (1969) A roll-tube method for cultivation of strict anaerobes. Methods Microbiol 3B, 117-132

Joblin KN (1981) Isolation, enumeration, and maintenance of rumen anaerobic fungi in roll tubes. $A p p /$ Environ Microbiol 42, 1119-1122

Kemp P, Jordan DJ, Orpin CG (1985) The free- and protein-amino acids of the rumen phycomycete fungi Neocallimastix frontalis and Piromas communis. J Agric Sci (Camb) 105, 523-526

Lowry OH, Rosebrough NJ, Farr AL, Randal! RJ (1951) Protein measurement with Folin phenol reagent. $J$ Biol Chem 193, 265-275

Maeng WJ, Van Nevel CJ, Baldwin RL (1976) Rumen microbial growth rates and yields: effect of amino acids and protein. J Dairy Sci 59, 68-79

Marounek M, Vovk SJ (1992) Distribution of radioactivity of ${ }^{14} \mathrm{C}$-amino acids added to the medium in cells and metabolites in cultures of rumen fungi. Reprod Nutr Dev 32, 129-133

Michel V, Fonty G, Millet L, Bonnemoy F, Gouet P (1993) In vitro study of the proteolytic activity of rumen anaerobic fungi. FEMS Microbiol Lett 110, 5-10

Onoda A, Kobayashi Y, Wakita M, Hoshino S (1993) Isolation of anaerobic phycomycete fungi from some herbivores and their chemical composition. Anim Sci Technol (Jpn) 64, 115-120 
Orpin CG, Greenwood Y (1986) Nutritional and germination requirements of the rumen chytridiomycete NeOcallimastix patriciarum. Trans Br Mycol Soc 86, 103-109

Phillips MW, Gordon GLR (1991) Growth responses to reduced sulphur compounds of a ruminal fungus. Neocallimastix sp LM1. In: Proc 3rd Internatl Symposium Nutr Herbivores (Malaysian Soc Anim Prod), 26
Wallace RJ, Joblin KN (1985) Proteolytic activity of a rumen anaerobic fungus. FEMS Microbiol Lett 29 , 19-25

Yanke LJ, Dong Y, McAllister TA, Bae HD, Cheng KJ (1993) Comparison of amylolytic and proteolytic activities of ruminal fung: grown on cereal grains. Can J Microbiol 39, 817-820 